\title{
Sevoflurane in patients at risk of ventricular dysrhythmias
}

\author{
Beny Charbit $^{1}$ (1)
}

Received: 24 February 2017 / Accepted: 23 March 2017 / Published online: 1 April 2017

(C) Japanese Society of Anesthesiologists 2017

Keywords QT interval · Sevoflurane · Propofol · Ventricular dysrhythmias

To the Editor:

I read with interest the paper by Terao et al. [1] that did not find QT prolongation in patients receiving propofol and sevoflurane during induction of anesthesia. However, it is probably more the consequence of low sevoflurane concentrations during induction than a 'counteract' effect of propofol on the electrophysiological effects of the volatile agent as stated by the authors. In fact, all volatile agents, including sevoflurane, prolong the QT interval due principally due to the inhibition of $\mathrm{I}_{\mathrm{HERG}}$ at clinical concentrations [2]. This inhibition of $I_{\text {HERG }}$ is involved in druginduced torsades de pointes [3]. Propofol does not have an inhibitory effect on $\mathrm{I}_{\text {HERG }}$ [4]. Thus, it is pharmacologically very improbable that propofol could counteract the cardiac effects of sevoflurane. Even if sevoflurane appears to be at a lesser risk than older volatile agents like isoflurane, it is probably safer to avoid these agents in patients at risk of ventricular dysrhythmias, contrary to the conclusions of
Terao et al. In these patients, propofol should be preferred, without sevoflurane, for both induction and maintenance of anesthesia [5], especially as the present work confirms the good electrophysiological tolerance of propofol.

\section{References}

1. Terao Y, Higashijima U, Toyoda T, Ichinomiya T, Fukusaki M, Hara T. The effects of intravenous anesthetics on QT interval during anesthetic induction with sevoflurane. J Anesth. 2016;30:929-34.

2. Li J, Correa AM. Kinetic modulation of HERG potassium channels by the volatile anesthetic halothane. Anesthesiology. 2002;97:921-30.

3. Roden DM. Drug-induced prolongation of the QT interval. N Engl J Med. 2004;350:1013-22.

4. Yamada M, Hatakeyama N, Malykhina AP, Yamazaki M, Momose Y, Akbarali HI. The effects of sevoflurane and propofol on QT interval and heterologously expressed human ether-ago-go related gene currents in Xenopus oocytes. Anesth Analg. 2006;102:98-103.

5. Staikou C, Chondrogiannis K, Mani A. Perioperative management of hereditary arrhythmogenic syndromes. Br J Anaesth. 2012;108:730-44.
This comment refers to the article available at doi:10.1007/ s00540-016-2252-8.

\section{Beny Charbit}

bcharbit@chu-reims.fr

1 Reims University Hospital, Reims, France 